\title{
Cancer and thrombosis: an increasingly important association
}

\author{
Wolfgang Korte
}

Published online: 22 February 2008

(C) Springer-Verlag 2008

Erratum to: Support Care Cancer

DOI 10.1007/s00520-007-0376-y

The footnote relating to presentation of the data at the MASCC/ISOO 20th Anniversary International Symposium was missing from the original publication.

The online version of this article can be found at http://dx.doi.org/ 10.1007/s00520-007-0376-y.

Presented as an invited lecture at the MASCC/ISOO 20th Anniversary International Symposium Supportive Care in Cancer in St Gallen, June 2007.

W. Korte $(\bowtie)$

Institut für Klinische Chemie und Hämatologie,

Kantonsspital, 9007 St., Gallen, Switzerland

e-mail: wolfgang.korte@ikch.ch 